\title{
APRENDENDO E EMPREENDENDO COM OS ERROS: SIGNIFICADOS E TRANSFORMAÇÕES DE EMPREENDEDORES PARTICIPANTES DO PROGRAMA SHARK TANK BRASIL
}

Jean Soares Da Silva ${ }^{1}$

${ }^{1}$ Mestrando no Programa de Pós-graduação em Administração da Universidade Federal da Paraíba - PPGA/UFPB 


\title{
APRENDENDO E EMPREENDENDO COM OS ERROS: SIGNIFICADOS E TRANSFORMAÇÕES DE EMPREENDEDORES PARTICIPANTES DO PROGRAMA SHARK TANK BRASIL
}

\begin{abstract}
Resumo: Relacionado as temáticas de Aprendizagem e Empreendedorismo, esse trabalho teve como objetivo analisar o processo de aprendizagem por erro de empreendedores participantes do programa Shark Tank Brasil que não conseguiram investimentos financeiros para seus negócios. Optou-se pela realização de uma pesquisa empírica, com abordagem qualitativa do tipo exploratória. A coleta dos dados aconteceu por meio de um roteiro de entrevista semiestruturado analisada em torno da temática da aprendizagem empreendedora e aprendizagem por erro, buscou-se entender as trajetórias do empreendedor, significados e percepções dos erros, processo de transformação e aprendizados. Em consonância aos aspectos teóricos, constatou-se no estudo que a experiência vivenciada pela participação no programa promoveu reflexões, transformações e aprendizados nos empreendedores, e consequentemente em seus negócios. Foi possível perceber o quão importante foi essa experiência para a trajetória dos empreendedores mudando a forma como eles encaram hoje o processo de aprender e empreender com os erros.
\end{abstract}

Palavras-chave: Empreendedorismo. Aprendizagem empreendedora. Aprendizagem por erro. Shark Tank Brasil.

\section{$1 \quad$ Introdução}

Por muito tempo as discussões sobre empreendedorismo e aprendizagem caminharam por direções não lineares. Contudo, a transição da perspectiva econômica do empreendedorismo para um olhar mais humano despertou o interesse de pesquisadores para investigarem não mais só as caraterísticas do empreendedor, mas seu processo de aprendizagem em virtude do ambiente dinâmico. A busca por relacionar as duas temáticas originou uma nova perspectiva denominada Aprendizagem Empreendedora.

Para Morrison e Bergin-Seers (2002) o aprendizado pode se alcançado através de ações práticas experienciais. A partir das experiências dos empreendedores, diversos fatores podem influenciar o seu processo de transformação para aprendizagem, até mesmo os erros. Porém, o interesse nos processos formais de aprendizagem (cursos, treinamentos e capacitações) pode descartar em alguns casos o papel dos erros em suas experiências e isso pode ser significativo no desenvolvimento do seu negócio.

Sendo assim, esse trabalho teve como objetivo analisar o processo de aprendizagem por erro de empreendedores participantes do programa Shark Tank Brasil que não conseguiram investimentos financeiros para seus empreendimentos.

O programa de Tv é uma franquia internacional exibida pelo Sony Channel onde empreendedores dos mais diversos tipos de negócios tentam convencer investidores altamente renomados no mercado à investirem seu próprio dinheiro nos empreendimento ali apresentados. Apenas duas saídas são possíveis no programa, consegui fechar negócio ou não! 
Olhando para os empreendedores que não conseguiram fechar negócio, quais os principais erros cometidos? Houve mudanças nos empreendimentos após a experiência de participar do programa? Quais foram os aprendizados?

Conforme Harteis, Bauer e Gruber (2008) até a última década ainda existiam poucas evidências empíricas que buscavam relacionar o fator erro como estímulo para aprendizagem. No contexto brasileiro, as pesquisas que investigam os erros no processo de aprendizagem estão mais imersas no campo de estudos da educação, diferente dos estudos Europeus e Americanos que já avançaram bem mais nessas discussões para uma perspectiva empresarial (BARBARINI, 2015).

Os questionamentos ora apresentados, assim como a percepção de lacunas na literatura, foram os principais motivantes para buscar alcançar o objetivo proposto. Zampier e Takahashi (2011) já sinalizavam que era oportuno o estudo empírico da aprendizagem empreendedora em uma abordagem construtivista experiencial. Portanto, esse estudo contribui para envolver os empreendedores na reflexão dos seus erros no processo de aprendizagem, como também avança nas discussões e perspectivas que a literatura sobre o tema propõe.

$\mathrm{O}$ artigo encontra-se estruturado da seguinte forma: após essa introdução; na segunda seção é abordado o referencial teórico; a terceira seção apresenta os procedimentos metodológicos que nortearam o estudo; a quarta seção analisa e discutem os resultados encontrados a partir das entrevistas realizadas com alguns empreendedores participantes do programa; e por fim, têm-se as considerações finais.

\section{Referencial Teórico}

Por muitos anos o empreendedorismo vem sendo foco de discussão nas ciências sociais. Para Pinto et al. (2010), essa temática ganha destaque principalmente nas economias desenvolvidas, dada sua contribuição para o aumento de renda, redução do desemprego e crescimento econômico. Timmons e Spinelli (2004) consideram o empreendedorismo uma revolução silenciosa que trará contribuições para o século XXI mais do que a revolução industrial trouxe para o século XX.

Por ser objeto de estudo tanto da Economia, da Psicologia e Administração, estudar empreendedorismo acaba ainda sendo muito complexo. Contudo, em virtude dos avanços na temática, a forma como o empreendedorismo vem sendo estudado está mudando. Segundo Matias et al. (2018) as discussões mais recentes vêm questionando a limitação dos estudos que até então eram mais voltadas para as características do empreendedor, porém, um olhar mais recente está se dedicando a estudar agora as ações empreendedoras.

Com uma definição bastante aceita entre os pesquisadores, Dornelas (2001) considera o empreendedor como o indivíduo que identifica oportunidades em seu meio e cria um negócio para capitalizar sobre ele, assumindo riscos calculados. Em outra visão, Hisrich e Peters (2004) já consideram o empreendedor como o indivíduo que combina seus recursos para tornar valor sobre um negócio, imerso em um processo dinâmico.

Essa última visão pode ser bastante aceita considerando o ambiente econômico volátil e competitivo que as organizações enfrentam nos últimos anos, forçando-as a mudarem rapidamente, se renovando, transformando e se adaptando para se manter compatíveis com seu contexto (LOPEZ; PEÓN; ORDÁZ, 2005). 
Filion (1999) já falava que, independente da geração em que o empreendedor esteja inserido, ele deve buscar evoluir constantemente, visando o contínuo aprendizado e detectando oportunidades em seu meio. Algo perceptível desde a visão de Schumpeter (1961) que em sua obra original considera o empreendedor como precursor de transformações através da destruição criativa.

Sendo assim, percebe-se que a aprendizagem é algo indispensável para evolução dos negócios. Bitencourt (2001) define aprendizagem como uma resposta às mudanças que as empresas enfrentam, onde a capacidade de aprender por meio de suas experiências, por exemplo, conduz os conhecimentos adquiridos em ações práticas que tornam a empresa mais competitiva.

$\mathrm{O}$ interesse em entender o processo de aprendizagem no contexto empreendedor abriu espaço para discussões de uma nova temática conhecida como Aprendizagem Empreendedora (AE), relacionando as teorias da aprendizagem organizacional e empreendedorismo, ambas já bem desenvolvidas e investigadas no universo acadêmico que contribuíram com pressupostos bem fundamentados para formulação desse novo termo (VOGT; BULGACOV, 2018).

\subsection{Aprendizagem empreendedora}

Foi a partir dos anos 80 que Tucker Jr. (1981) abordou diretamente em seu estudo esses dois temas. Conforme percebido por Wang e Chugh (2014), não havia até então na literatura uma relação fortemente estabelecida entre aprendizagem e empreendedorismo. Mesmo com o interesse e inquietações de alguns pesquisadores para essa temática, a expressão "aprendizagem empreendedora" só veio aparecer realmente no trabalho de Murphy (1993) e foi utilizada enquanto temática para identificar uma área de estudo somente no final dos anos 90 (VOGT; BULGACOV, 2018).

Diferentes perspectivas de estudos foram desenvolvidas na Aprendizagem Empreendedora para orientar as possibilidades de investigação no campo. Conforme Man (2006) as pesquisas seguem um enfoque cognitivo, experiencial e de networking.

A abordagem cognitiva considera a aprendizagem empreendedora um processo mental onde o empreendedor adquire, estoca e usa seu conhecimento em longo prazo (ZAMPIER; TAKAHASHI, 2011). A abordagem experiencial segue a orientação de Kolb (1984) a partir de seu modelo de aprendizagem onde o indivíduo é constantemente modificado por suas experiências e reflexões. Por fim, na abordagem de networking, as redes de relacionamentos composta por amigos, mentores, empresas parceiras, fornecedores e outros, contribuem para as habilidades e conhecimentos dos empreendedores (ZAMPIER; TAKAHASHI, 2011).

Para este estudo, tem-se como base a definição de aprendizagem empreendedora experiencial. Esse tipo de aprendizagem por ser definido como: um processo de interação social onde os indivíduos por meio de seus aprendizados identificam oportunidades de negócios e aprendem a administrar o seu empreendimento com os conhecimentos adquiridos por experiências anteriores e com experiências atuais (POLITIS, 2005; RAE; 2000; RAE; CARSWELL, 2000).

Visitando a literatura sobre AE dois estudos se destacam entre os demais, Kolb (1984) conhecido por ter formulado a teoria da aprendizagem experiencial, e Politis (2005) que avançou no estudo proposto por Kolb (1984) propondo um modelo de aprendizagem com 
enfoque mais dinâmico para o empreendedor. A fundamentação deste trabalho busca mesclar as bases conceituais propostas pelos dois autores. Ambos os estudos possuem suas percepções e particularidades, mas em comum segue uma linha construtivista experiencial, assim como esse trabalho.

Para Kolb, Rubín e Mcintyre (1978), o processo de aprendizagem se refere à capacidade do indivíduo de experimentar e aceitar riscos para resolver e dominar os problemas do seu dia a dia. Os autores ainda consideram que a experiência concreta é atrelada por observação e reflexão, onde são formulados conceitos abstratos e generalizações que contribuem para o surgimento de hipóteses que serão testadas nas ações futuras, proporcionando novas experiências. A direção da aprendizagem é orientada pelas necessidades sentidas e pelos objetivos que indivíduo possui (KOLB; RUBÍN; MCINTYRE, 1978).

Nisso, o modelo de aprendizagem que foi desenvolvido por Kolb (1984) trata das experiências, reflexões, memória e conhecimentos próprios para interpretações do ambiente e criação de planos de ação. Por tanto, a aprendizagem é vista como um processo que possui tentativa e erro, onde as ideias são formadas e transformadas por meio das experiências.

Com uma visão mais abrangente, Politis (2005) argumenta que a experiência prévia na criação de negócios, é muito importante para a aprendizagem empreendedora, uma vez que, os conhecimentos adquiridos nessas experiências influenciam suas decisões estratégicas. $\mathrm{O}$ seu modelo tem como foco o processo de transformação das experiências dos empreendedores.

O estudo de Politis (2005) se destaca por integrar as teorias da aprendizagem experiencial no campo do empreendedorismo, distinguir a experiência empreendedora e o conhecimento adquirido, e focar de forma mais dinâmica em um processo intermediário onde os conhecimentos são transformados constantemente.

Marsick e Watkins (1997) já apontavam que todo o aprendizado é passível de erros. Os autores destacaram que as principais fontes desses erros são: um mau diagnóstico das situações; falta de contextualização; solução inadequada; aprendizagem de habilidades insuficientes; falta de visão das consequências; generalizações incorretas; e inadequação na estruturação do problema.

Por meio disso, cada vez mais a habilidade para aprender vem se tornando importante no contexto do empreendedor, principalmente pelas rápidas mudanças que acontecem no mundo dos negócios (DIAS; MARTENS, 2016). Para Priyanto e Sandjojo (2005) a aprendizagem pode acontecer por diversas formas e até mesmo as crises e os erros são importantes para o empreendedor, pois exigem reflexão e ação que contribuem para seu processo de aprendizagem.

\subsection{Aprendizagem por erro}

Mesmo que a temática de aprendizagem por erros ainda seja recente, há evidências de que a forma como a organização, o individuo ou as equipes lhe dão com os erros podem ser efetivas para a aprendizagem (PUTZ et al., 2012). Em grande parte, os erros estão inclusos no contexto da aprendizagem informal e não ocorre necessariamente por cursos e capacitações, mas através de experiência inesperadas nos negócios (MARSICK; WATKINS, 2003). 
Para Cannon e Edmondson (2001) essas falhas são compreendidas como desvios do negócio que diferem daquilo que se esperava como resultado e aconteceram de forma errada mesmo que evitáveis ou inevitáveis, pois a empresa assumiu o risco na sua tomada de decisão. Os empreendedores sabem que a ocorrências dos erros podem comprometer em alguns casos o desenvolvimento de seu negócio, trazer prejuízos e perdas, e por isso tentam ao máximo evitá-los. Contudo, assim como expressa Bauer e Mulder (2007), os erros fazem parte de um processo natural que levam a organização a fazer mudanças.

Nesse momento, as competências e habilidades do empreendedor são colocadas à prova. Para Harteis, Bauer e Gruber (2008) o compromisso que o indivíduo tem em refletir os erros e construir um conhecimento a partir dele, é o que configura aprendizagem. Balestrin (2007) ressalta que, os manuais, normas e procedimentos de uma organização ajudam muito na solução de problemas, porém, o processo reflexivo pelos erros acaba incentivando a criatividade e inovação nos processos. Essa aprendizagem menos estruturada é mais significativa para o negócio (MARSICK; WATKINS, 2003).

Assim como defendem Cannon e Edmondson (2005) é possível ocorrer aprendizagem a partir dos erros, mas são necessárias habilidades gerenciais. O empreendedor, muitas vezes é o gestor de seu negócio, e nesse momento é desafiado a colocar em práticas suas habilidades ou até mesmo desenvolver outras novas, assim, é possível tirar vantagens das lições aprendidas com os erros que aconteçam em sua trajetória.

Em uma revisão da literatura Putz et al. (2012) identificaram quatro estágios sobre o processo de aprendizagem a partir dos erros: detecção, atribuição/lidar com emoções, análise e correções e disseminação das experiências.

Quadro 1. Atividades de aprendizagem e estágios dos processos de aprendizagem relacionados aos erros

\begin{tabular}{|c|c|c|c|c|}
\hline Fonte & Detecção de erros & $\begin{array}{l}\text { Atribuição do Erro / } \\
\text { Lidar com emoções }\end{array}$ & $\begin{array}{c}\text { Análise e correção } \\
\text { dos erros }\end{array}$ & $\begin{array}{c}\text { Disseminação das } \\
\text { experiências }\end{array}$ \\
\hline $\begin{array}{l}\text { Bauer et al., } \\
\text { 2005; Bauer e } \\
\text { Mulder, } 2007\end{array}$ & $\begin{array}{l}\text { Experiência de erro } \\
\qquad(2007)\end{array}$ & $\begin{array}{l}\text { Reação emocional } \\
\qquad(2007)\end{array}$ & $\begin{array}{l}\text { Reflexão sobre as } \\
\text { causas de erros; } \\
\text { reflexão sobre } \\
\text { estratégias de ação } \\
\text { alternativas }\end{array}$ & Intercâmbio social \\
\hline $\begin{array}{c}\text { Cannon e } \\
\text { Edmondson, } \\
2001,2005 \\
\end{array}$ & $\begin{array}{l}\text { Identificação da } \\
\text { falha }\end{array}$ & $\begin{array}{l}\text { Manejo produtivo do } \\
\text { conflito (2001) }\end{array}$ & $\begin{array}{l}\text { Análise de falhas, } \\
\text { Experimentação } \\
\text { deliberada (2005) }\end{array}$ & $\begin{array}{l}\text { Discussão das } \\
\text { falhas }\end{array}$ \\
\hline $\begin{array}{l}\text { Chiva et al., } \\
2007\end{array}$ & & $\begin{array}{l}\text { Tomada consciente de } \\
\text { riscos }\end{array}$ & Experimentação & $\begin{array}{l}\text { Diálogo, tomada } \\
\text { de decisão } \\
\text { participativa, } \\
\text { interação com } \\
\text { ambiente externo }\end{array}$ \\
\hline $\begin{array}{c}\text { Edmondson, } \\
1999\end{array}$ & $\begin{array}{l}\text { Busca de } \\
\text { retroalimentação }\end{array}$ & Solicitação de ajuda & Experimentar & $\begin{array}{l}\text { Compartilhar } \\
\text { informação }\end{array}$ \\
\hline Kolodner, 1983 & Percepção da falha & Atribuição de culpa & $\begin{array}{l}\text { Correção da falha, } \\
\text { explicação da falha }\end{array}$ & \\
\hline Ohlsson, 1996 & Detecção de erros & & Correção de erros & \\
\hline $\begin{array}{l}\text { Ramanujam e } \\
\text { Goodman, } \\
\text { 2003; }\end{array}$ & Atenção ampliada & $\begin{array}{l}\text { Não-aceitação de } \\
\text { comportamentos } \\
\text { Irregulares }\end{array}$ & Correção de erros & \\
\hline
\end{tabular}




\begin{tabular}{|c|c|c|c|c|}
\hline Fonte & Detecção de erros & $\begin{array}{c}\text { Atribuição do Erro / } \\
\text { Lidar com emoções }\end{array}$ & $\begin{array}{c}\text { Análise e correção } \\
\text { dos erros }\end{array}$ & $\begin{array}{c}\text { Disseminação das } \\
\text { experiências }\end{array}$ \\
\hline $\begin{array}{c}\text { Tjosvold et al., } \\
2004\end{array}$ & $\begin{array}{c}\text { Acusação de outros } \\
\text { por erros }\end{array}$ & $\begin{array}{c}\text { Análise e correção de } \\
\text { problemas }\end{array}$ & $\begin{array}{c}\text { Discussão e troca } \\
\text { de experiências } \\
\text { sobre erros }\end{array}$ \\
\hline $\begin{array}{c}\text { Van Dyck et al., } \\
2005\end{array}$ & $\begin{array}{c}\text { Detecção de erros e } \\
\text { controle de danos }\end{array}$ & $\begin{array}{c}\text { Ajuda em situações } \\
\text { de erros }\end{array}$ & $\begin{array}{c}\text { Analisar erros, } \\
\text { manejo efetivo dos } \\
\text { erros }\end{array}$ & $\begin{array}{c}\text { Cominicação } \\
\text { sobre erros, troca } \\
\text { conhecimento } \\
\text { sobre erros, } \\
\text { coordenação de } \\
\text { manejo de erros }\end{array}$ \\
\hline $\begin{array}{c}\text { Van Woerkom e } \\
\text { Croon, 2008 }\end{array}$ & $\begin{array}{c}\text { Trabalho reflexivo, } \\
\text { abertura sobre } \\
\text { erros, pedido de } \\
\text { retroalimentação }\end{array}$ & $\begin{array}{c}\text { Troca de opiniões } \\
\text { críticas, desafio } \\
\text { aos padrões do } \\
\text { grupo }\end{array}$ \\
\hline $\begin{array}{c}\text { Zhao e Olivera, } \\
\text { 2006 }\end{array}$ & $\begin{array}{c}\text { Detecção de erros } \\
\text { benefício do reporte } \\
\text { de erros, evitar } \\
\text { emoções negativas }\end{array}$ & Manejar os erros & $\begin{array}{c}\text { Reporte de Erros } \\
\text { Experimentação }\end{array}$ \\
\hline
\end{tabular}

Fonte: Putz et al. (2012, p. 514) traduzido e adaptado por Barbarini (2015)

Segundo Barbarini (2015), as reações aos erros podem incluir aspectos presentes tanto em um estágio como em outro e isso aumenta a habilidade do indivíduo para lidar com os erros. Essa abordagem sistemática que considera os quatro estágios para aprender com os erros utiliza todo o potencial do ocorrido para o desenvolvimento do indivíduo e do seu negócio. O modelo proposto pode ser aplicado tanto em atividades planejadas e executadas, como nas reações espontâneas aos erros (PUTZ et al., 2012).

\section{$3 \quad$ Metodologia}

Para o percurso metodológico, optou-se pela realização de uma pesquisa empírica, com abordagem qualitativa do tipo exploratória. A escolha pelo método qualitativo apresentou-se como o mais adequado para atingir o objetivo desse estudo que foi compreender o fenômeno da aprendizagem empreendedora a partir dos erros. Para justificar a escolha do pesquisador, Merriam (2002) expressa que, a pesquisa qualitativa é a mais coerente quando se pretende entender um fenômeno social com maior proximidade. A abordagem qualitativa também permite mais abertura para compreensão dos dados (DE SOUZA MARTINS, 2004).

A coleta dos dados aconteceu por meio de um roteiro de entrevista semiestruturado com 13 perguntas em torno da temática do estudo. O roteiro emergiu das dimensões e elementos constitutivos da aprendizagem empreendedora (KOLB, 1984; POLITIS, 2005) e aprendizagem por erro (PUTZ et al., 2012) buscando analisar trajetórias do empreendedor, significados e percepções dos erros, processo de transformação e aprendizados.

O contexto do estudo foram alguns empreendedores que participaram do programa de Tv Shark Tank Brasil - Negociando com Tubarões, versão brasileira do reality show norteamericano Shark Tank exibido pelo Sony Channel. Na série, empreendedores diversos são convidados para apresentar seu empreendimento para uma bancada de especialistas de 
negócios denominados "tubarões", empresários que possuem grande experiência e capacidade de investimentos financeiros de alto valor.

Ao participar do programa os empreendedores oferecem uma parte do seu negócio em troca de investimento. Os principais nomes nesse grupo de "tubarões" são: João Appolinário, proprietário e fundador da Polishop; Cristiana Arcangeli, proprietária da linha Beautyin; Robinson Shiba, fundador do China in Box; Camila Farani, empresária e investidora Anjo, Caito Maia, fundador da Chilli Beans; e Carlos Semenzato, fundador da SMZTO franquias.

No segundo semestre de 2019, a franquia lançou uma série de vídeos intitulada "Nadando Sozinho" com cinco empreendimentos que mesmo não recebendo investimento dos "tubarões" foram capazes de alavancar seus negócios impulsionados pela experiência e aprendizados adquiridos com o programa, além de sua trajetória empreendedora.

O interesse de investigar a temática Aprendizagem empreendedora por erros, alinhado à experiência desses empreendedores que correspondiam o perfil desejado, levou a escolhê-los como sujeitos da pesquisa.

Quadro 2 - Perfil dos empreendedores participantes da pesquisa

\begin{tabular}{|c|c|c|c|c|}
\hline Empreendedor & Idade & Formação & Empresa & $\begin{array}{l}\text { Setor de } \\
\text { atuação }\end{array}$ \\
\hline $\begin{array}{l}\text { Claudio } \\
\text { Santiago }\end{array}$ & 42 & $\begin{array}{c}\text { Graduação em Administração com MBA } \\
\text { em Gestão Comercial }\end{array}$ & $\begin{array}{l}\text { Escape Time } \\
\text { Brasil }\end{array}$ & Serviço \\
\hline $\begin{array}{l}\text { Leonardo de } \\
\text { Matos }\end{array}$ & 44 & $\begin{array}{l}\text { Graduação em Direito com MBA em } \\
\text { Marketing, Administração e Negócios }\end{array}$ & $\begin{array}{l}\text { Bosta em } \\
\text { Lata }\end{array}$ & Comércio \\
\hline Karlos Brasília & 41 & $\begin{array}{l}\text { Graduação com Bacharelado e Licenciatura } \\
\text { em Educação Física }\end{array}$ & 2GoBag & Comércio \\
\hline Bruna Lopes & 41 & $\begin{array}{c}\text { Graduação em Medicina Veterinária com } \\
\text { Mestrado em Medicina Veterinária } \\
\text { Preventiva }\end{array}$ & Bicho de Pet & $\begin{array}{c}\text { Comércio e } \\
\text { Serviço }\end{array}$ \\
\hline Diogo Petri & 40 & $\begin{array}{l}\text { Especialização em Vendas, Merchandising e } \\
\text { Marketing }\end{array}$ & \multirow[b]{2}{*}{ CatMyPet } & \multirow[b]{2}{*}{ Comércio } \\
\hline Agnes Cristina & 35 & $\begin{array}{c}\text { Graduação em Comunicação Social com } \\
\text { Pós-graduação em Gestão de Negócios com } \\
\text { ênfase em Marketing }\end{array}$ & & \\
\hline
\end{tabular}

Fonte: Elabora pelo autor (2019)

As entrevistas para coleta dos dados foram realizadas em outubro de 2019 em horários previamente agendados com os empreendedores. Como todos os participantes residiam em Estados diferentes do pesquisador, as entrevistas acontecerem por chamadas de vídeos através de Skype, Hangouts e WhatsApp, com duração média de 34 minutos. Todas as entrevistas foram gravadas com devida autorização, e transcritas na íntegra para ampliar o acesso público aos resultados e ajudar no detalhamento dos dados, como recomenda Godoi e Mattos (2006).

A análise dos dados seguiu os pressupostos da análise do discurso. Por ser uma prática interpretativa com abordagem transdisciplinar ampla e teórica (GODOI, 2006) a análise dos dados não foi limitada a uma série de passos e procedimentos técnicos como em outros procedimentos. Para Roesch (2006), o foco dessa análise está na variação da linguagem para entender os significados e propósitos dos discursos. 


\section{$4 \quad$ Resultados e discussões}

Os empreendedores foram questionados sobre sua trajetória de mercado antes de empreenderem suas atuais atividades. Todos falam sobre suas experiências profissionais ou como foram empreendedores em outros negócios que não deram muito certo. Na maioria, é perceptível o quanto suas atividades anteriores refletiram as decisões para suas novas ações, o que levou os empreendedores dedicarem esforços para fazer aquilo que gostavam e tinham paixão. Nos discursos, percebe-se a construção de uma maturidade empreendedora.

O fator de já ter "quebrado" uma empresa, assim como afirma o empreendedor Leornado, o fez pensar sobre suas capacidades e habilidades enquanto empreendedor, levando-o a se dedicar no seu novo empreendimento naquilo que ele diz ser bom: fazer vendas. As experiências do empreendedor Claudio também o ajudaram a decidir com o que ele não queria mais trabalhar. Cláudio relata que fez uma listagem do que gostava e do que não gostava e queria "trabalhar com coisas legais que, educasse e ajudasse as pessoas. [...] Trabalhar com recursos intelectuais do que físicos...”.

Quando questionados sobre a oportunidade de participar do programa, quase todos os empreendedores afirmam que não precisavam necessariamente de grandes investimentos financeiros para o seu negócio, pois eram valores que poderiam conseguir em linhas de créditos de instituições financeiras. Participar do programa era vista como uma oportunidade única de impacto para o negócio.

Os empreendedores Karlos e Leonardo sabiam que a participação no programa seria uma grande oportunidade de mídia para seus negócios, evidenciando Dornelas (2001) quando fala que o empreendedor é aquele que percebe oportunidades. Para o empreendedor Claudio, o know-how dos "tubarões" era o que mais lhe interessava, independente de consegui o investimento ou não:

[...] A gente foi lá primeiro em busca de alguém que já conhece sobre negócios, que já trabalhou e pudesse dar uns insights bacana. Essa é a maior riqueza que a gente estava buscando lá. Ter um sócio com calibre para algumas coisas que são discutidas lá é interessante porque te faz pensar um monte de coisa e a se questionar. (Claudio)

O empreendedor ainda acrescenta sobre a necessidade de avaliação para os empreendedores de maneira geral, como se muitos fossem acomodados sobre o seu negócio e seguissem apenas as tendências de mercado, não colocando o empreendimento à prova.

[...] Quando você é empreendedor o maior problema que eu vejo é que você não tem massa crítica para te questionar o tempo todo. [...] Você tem uma equipe geralmente abaixo e ninguém te questiona no nível estratégico, questiona no nível funcional. Então esse questionamento acaba faltando para o empreendedor e aí ele acabando indo meio pela maré, por que estrategicamente falando ele não é questionado quanto ao seu planejamento. (Claudio)

Como já afirmava Marsick e Watkins (2003) as pessoas não possuem o costume de fazer questionamentos da sua visão ou da visão apresentadas por outros membros da organização, e isso pode distanciá-los da compreensão dos erros e consequentemente de seu aproveitamento. Por tanto, além da questão financeira, a principal importância atribuída ao 
programa por muitos dos empreendedores era voltada para os questionamentos dos "tubarões".

O estudo revela que tanto as experiências dos empreendedores em atividades passadas, como suas rotinas nos negócios atuais, também promoveram alteração em seus esquemas de significados para os erros. Percebe-se que os empreendedores tem uma visão "positiva" dos erros, e acreditam que eles contribuíram para aprendizados em seus negócios.

Erro para mim faz parte do processo de aprendizagem e a gente tem que errar para aprender da melhor maneira possível no primeiro erro, minimizar no segundo e assim até acertar sucessivamente o que você tá pretendendo fazer. (Karlos)

Eu não considero erros, eu considero ajustes. Errar todo mundo erra, mas com toda boa intenção que a gente tem de sempre acertar a gente vai errar! Mas, errou rápido, corrige rápido. (Bruna)

Na mesma percepção de Bauer e Mulder (2007), os empreendedores consideram os erros como um processo natural nos negócios, o desafio para os empreendedores está em identificá-los, a fim de minimizar os danos e extrair deles algum aprendizado, assim como fala Cannon e Edmondson (2001). Tanto para os empreendedores Claudio e Leonardo, os erros podem ser perceptíveis de duas formas: contornáveis ou comprometedores, para eles, o primeiro está ligado às questões mais operacionais e o segundo à estratégia do negócio, sendo esse último o mais arriscado para o empreendedor.

No programa Shark Tank Brasil, essas duas formas de erros podem ser percebidos e apontados pelos "tubarões" e isso pode comprometer o interesse em investir no negócio. Mesmo o empreendimento sendo bem estruturado ou inovador, foi possível perceber um reconhecimento por parte dos empreendedores de que fizeram algo errado. Muitos dos erros estavam ligados às decisões estratégicas apresentadas aos investidores, porém, até mesmo os casos mais simples em que os erros se davam por pouca preparação e conhecimento técnico, foram comprometedores e resultaram os empreendedores a não fecharem negócio.

\footnotetext{
A gente estava em um momento que precisava muito de capital, então foi bem difícil tomar aqueles "não" porque a gente acreditava muito no negócio, né? Então a gente pensava: "poxa, a gente tem faturamento, tem um produto bacana, tem um mercado bacana, porque é que a gente não tá conseguindo? O que é que está faltando? (Agnes)
}

Quando a gente saiu do programa, agente tinha três hipóteses por eles não terem investido: uma hipótese era o mercado não ser tão bom como a gente estava enxergando; a outra hipótese era o nosso modelo de negócio e o produto não ser tão bom; e a outra hipótese foi a gente não ter sabido vender da melhor forma. [...] A gente só sabia fazer acontecer, não sabia fazer o melhor discurso. [...] Então realmente a agente estava despreparado para esse tipo de análise que o investidor gosta de fazer. [...] A gente não sabia se posicionar, então a gente era muito inseguro e não sabia valorizar o nosso negócio no montante que ele estava, porque ainda estávamos aprendendo a expor ele. (Agnes)

Mesmo muitos dos empreendedores relatarem que não buscavam necessariamente o investimento financeiro, percebe-se que a oportunidade de participar do programa criou 
expetativas para fechar negócio. O fato de não terem conseguido o investimento levou os empreendedores para um mar de reações emotivas, conforme explica Bauer e Mulder, 2007.

No discurso, os entrevistados relatam que sentiram decepção, chateação, frustração e tristeza. Compreende-se que, da mesma forma que essas reações podem contribuir para o processo de reflexão do empreendedor, também podem ser limitantes caso o indivíduo não possua maturidade para extrair aprendizados da experiência. $\mathrm{Na}$ entrevista, os empreendedores relatam em seus discursos que após absorverem todo o ocorrido foram capazes de compreender o que era necessário fazer ou não para seu negócio prosperar.

Chorava... eu só chorava. Meu consultor achou que eu me sai super bem na apresentação, mas eu chorava porque pensava: "meu Deus, eu não consegui o investimento". Mas depois eu entendi que foi o melhor dos mundos para mim. [...] Eu demorei uns 15 dias para digerir. Eu fiquei triste, eu chorei, eu achei que isso tivesse sido uma coisa negativa, e hoje eu entendo que foi absolutamente positivo... (Bruna)

A primeira coisa que veio foi uma frustração. Eu conheço tanto meu negócio, como é que não deu certo? Como é que eu fiz outra pessoa não acreditar? Então a primeira coisa que a gente fez, eu e meu sócio, foi uma reflexão sobre o que faltou e por quê? Então depois de algumas semanas nessa reflexão a gente chegou numa conclusão. [...] Isso nos fez repensar nosso modelo de crescimento. (Claudio)

[...] A gente fica meio chateado assim na hora com os essas críticas, mas isso passou rapidinho e eu falei: "vamos absorver o que esses caras estão falando pra gente fazer tudo ao contrário. (Leonardo)

Falaram que a gente ia vender uma vez só, por exemplo, por causa do apelo da brincadeira. Porém eu pensei: "não, eu não posso vender uma vez só, eu tenho que ter vendas recorrentes". Então eu fui atrás de desenvolver o melhor adubo orgânico do mundo, então foi o que aconteceu e hoje a gente tem vendas super recorrentes. (Leonardo)

Harteis, Bauer e Gruber (2008) falam que, o processo reflexivo serve para orientar situações futuras, sem isso, o conhecimento oriundo pelos erros torna-se sem utilidade. Por meio disso, com a experiência de participar do programa, os empreendedores revelaram que as transformações em seus negócios aconteceram de forma mais natural, ao invés de mudanças estabelecidas rigidamente.

Alguns procuraram em um primeiro momento o apoio de consultorias e capacitações, e faziam alterações nos negócios se achassem necessárias, como: treinamento dos colaboradores, melhorias no produto ou serviço e decisão de expansão do negócio. De modo contrário, a empreendedora Agnes relata que ela e o seu sócio não foram exatamente atrás de um processo formal de capacitação devido a limitação dos recursos financeiros da empresa, mas procuravam outras pessoas que já tinham experiências de mercado para conversar, nisso, eles faziam uma espécie de "mentoria rápida" na medida em que construíam os seus conhecimentos de forma orgânica.

Além disso, observou-se também que alguns dos empreendedores entrevistados mesmo acreditando que o planejamento formal seja importante para os negócios, seus discursos revelam que a realidade do empreendedor exige agilidade para assumir riscos e que as 
decisões do empreendedor não são pautadas exatamente só no planejamento, mas em situações emergentes e do feeling empreendedor.

[...] Eu não sou um cara de fazer planejamento a longo prazo, eu acho que um negócio desse tamanho a gente tem que colocar a mão na massa e ir ajustando conforme vai tendo as respostas do mercado e dos clientes, do que um planejamento engessado a longo prazo e correr o risco de ter um prejuízo muito maior.(Karlos)

Olha, eu vou te falar que eu tô indo um pouco no embalo. Tudo meu tem planejamento, eu não sou uma pessoa que sai fazendo as coisas sem planejar, né? Mais uma vez eu te digo, quando a gente acredita no potencial do negócio, quando você coloca o seu coração ali, a chance de dar errado é muito baixa. (Bruna)

A partir da fala da empreendedora Bruna, percebe-se que no processo de empreender os sentimentos para com o negócio são muito importantes para diminuir as chances de erro. É certo que existem uma série de fatores internos e externos inevitáveis que podem influenciar todo o negócio, mas entende-se que esse sentimento colocado ao negócio faz com que o empreendedor reflita ao máximo sobre as ações necessárias para o bom funcionamento do empreendimento.

O empreendedor Leonardo relata que, hoje, se cometer erros comprometedores em seu empreendimento, é como se estivesse "dando um tiro" em si próprio, por isso tem bastante cautela na gestão de seu negócio. Nos discursos, é como se os empreendedores atribuíssem vida ao seu negócio, que deve ser cuidado como uma pessoa para evitar doenças (erros) e não morrer (fechar o negócio).

Para os entrevistados, o aprendizado adquirido com a experiência no Shark Tank Brasil vai além de participar de um programa de Tv, mas a forma como ele induz os empreendedores à saírem de sua zona de conforto para evoluírem em seus aprendizados, independente do investimento financeiro.

A gente viu que antes de participar do Shark Tank, a gente ficava muito na empresa, ali na operação, dentro da casinha, né? [...] Não saíamos para fora e nem participávamos de eventos. Depois do Shark Tank a gente mudou esse posicionamento. Começamos a dar palestras, a ser chamado em eventos e fazendo networking. E a gente viu que você fazendo networking, conhecendo as pessoas, e conhecendo as pessoas certas, vale mais que dinheiro. (Diogo)

Não tem tanto a ver com o programa, tem a ver com o jeito da pessoa de encarar a vida. A gente, eu e o Diogo, teve a experiência ruim, porque a gente não foi investido e precisava do investimento. [...] Mas a gente sempre olhou o lado positivo do programa. [...] Apesar de tudo isso, de ter ficado triste e tudo, mas ainda assim a gente acha que é melhor do que não existir, porque o mercado ele é assim. (Agnes)

O empreendedor Claudio relata que "qualquer outro programa que tivesse pessoas ali com conhecimento explícito te questionando sobre o seu negócio, isso é muito rico...". Na mesma linha de pensamento, o empreendedor Leonardo aconselha outros empreendedores "ter um feedback de pessoas neutras que não vão falar o que você quer ouvir, necessariamente". 
Também, o empreendedor Karlos recomenda que os empreendedores tenham senso de oportunidade para saber quais são as experiências que vão contribuir com seu negócio, mesmo que você cometa alguns erros. A empreendedora Bruna relata que não modificou a sua maneira de ser, mas que passou por um processo de amadurecimento enquanto empresária depois de ter participado do Shark Tank Brasil.

Já a empreendedora Agnes, acredita que o programa, como também sua trajetória empreendedora, lhe ajudou a ter mais autonomia e autoridade na carreira para se relacionar no mercado. Enquanto isso, para o seu sócio Diogo que sempre foi da parte comercial da empresa, sentia uma barreira para falar com um lojista ou um veterinário por serem especialistas na área de seus produtos, mas a sua trajetória e o programa também lhe conferiram mais confiança enquanto representante do seu empreendimento.

É importante ressaltar, que o caso especifico de Agnes e Diogo, sócios do CatMyPet, foi um dos poucos empreendimentos a voltar para o "tanque" de avaliação do Shark Tank Brasil. Com toda a experiência e aprendizados adquiridos com a primeira participação no programa, os empreendedores se inscreveram novamente dois anos depois e mostraram que estavam preparados para o investimento. Como resultado, conseguiram fechar uma sociedade com João Appolinário, presidente e proprietário fundador da Polishop, e com Camila Farani, uma das maiores empresárias e investidoras anjo do Brasil.

Tendo como referência a interpretação e análise dos discursos apresentados, a Figura 1 sistematiza como ocorreu o processo de aprendizagem por erros desses empreendedores que participaram do Shark Tank Brasil, considerando o significado dos erros, sua percepção, o processo de transformação, e o que foi aprendido com eles.

Figura 1 - Aprendizagem por erros dos empreendedores participantes do Shark Tank Brasil

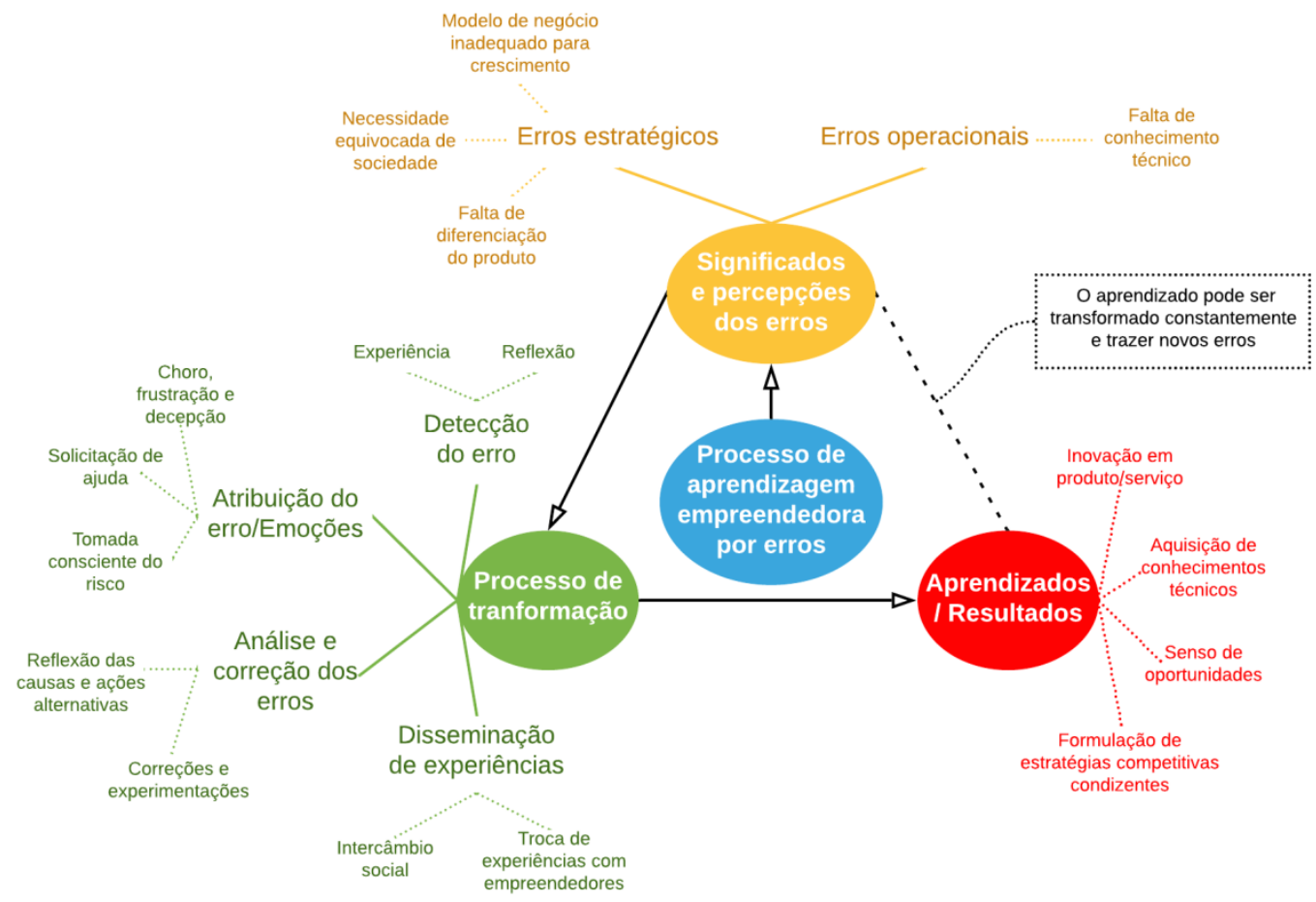

Fonte: Elaborado pelo autor (2019) 
É importante ressaltar que a figura 1 não representa um modelo teórico-empírico de como acontece o processo de aprendizagem empreendedora por erros, mas uma ilustração de como ocorreu de modo específico essa aprendizagem no contexto de alguns empreendedores que participaram do Shark Tank Brasil e que foram capazes de aprender com a experiência e seus erros para alavancar seus negócios.

Portanto, analisando os relatos dos empreendedores em consonância aos aspectos teóricos, principalmente pelos os estudos de Kolb (1984), Politis (2005) e Putz et al. (2012), constatou-se nessa pesquisa que a experiência vivenciada pela participação no programa promoveu reflexões, transformações e aprendizados nos empreendedores, e consequentemente em seus negócios. Foi possível perceber o quão importante foi essa experiência para a trajetória dos empreendedores mudando a forma como eles encaram hoje o processo de aprender e empreender com os erros.

\section{$5 \quad$ Considerações}

Este estudo investigou o processo de aprendizagem por erros de empreendedores participantes do programa Shark Tank Brasil. Analisar o processo de aprendizagem empreendedora pode ser complexo por envolver um conjunto de elementos relacionados que afetam significados, reflexões e transformação dos empreendedores, principalmente quando o erro é o foco de análise.

Os resultados aqui apresentados indicam que a participação no programa de $\mathrm{Tv}$ contribuiu para o processo de aprendizagem, mas não se pode concluir que experiências dos erros cometidos no programa foram os mais significativos para essa aprendizagem empreendedora. Aspectos como experiências profissionais e de outros negócios, assim como conhecimentos anteriores e questões vinculadas ao ambiente de aprendizagem podem também ter atuando como fatores mediadores no processo.

Contudo, com a análise dos resultados aqui apresentados, já é possível perceber um alto nível de maturidade na forma como os empreendedores superaram seus desafios. O estudo também revela a necessidade dos empreendedores de refletirem sobre a participação em ações que promovam o desenvolvimento de competências empreendedoras, pois esse tipo de experiência não acontece necessariamente só por esse programa, mas sim por qualquer outra atividade que reflita o dia a dia do contexto empreendedor, que estão sempre querendo melhorar e aprender com seus erros e acertos.

Essa reflexão sobre o processo de aprendizagem empreendedora à luz da aprendizagem por erros contribui para melhorias na gestão empreendedora, principalmente para os que estão começando agora. Além disso, o estudo amplia a compreensão desse tipo de aprendizagem abrindo oportunidades de investigação para outras pesquisas com aplicação de métodos quantitativos que busquem analisar nesse processo de aprendizagem quais fatores e erros são mais determinantes para transformações e aprendizados nos empreendedores e sua relação para o desenvolvimento de competências e habilidades empreendedoras.

Em linhas gerais, acredita-se que esse estudo conseguiu atingir o objetivo ao qual se propôs e que contribui para novas reflexões sobre a ação empreendedora e consequentemente para o avanço de novas possibilidades de investigação no campo. 


\section{Referências}

BALESTRIN, A. Criação de conhecimento organizacional: teorizações do campo de estudo. Organizações \& Sociedade, v. 14, n. 40, p. 153-168, 2007.

BARBARINI, A. C. Fatores organizacionais que influenciam a aprendizagem a partir dos erros e sua relação com os comportamentos inovadores no trabalho em uma empresa do segmento farmacêutico. 2015. Dissertação (Mestrado em Administração) Universidade Presbiteriana Mackenzie.

BAUER, J.; FESTNER, D.; GRUBER, H.; HARTEIS, C.; HEID, H. Error culture in the workplace: Differences between managers and staff members. In: GRUBER, H.; HARTEIS, C.; MULDER, R. H. et al. Bridging Individual, Organizational, and Cultural Perspectives on Professional Learning. Regensburg: Roderer, p. 259-263, 2005.

BAUER, J.; MULDER, R. H. Modeling learning from errors in daily work. Learning in health and social care, v. 6, n. 3, p. 121-133, 2007.

BITENCOURT, C. C. A gestão de competências gerenciais: a contribuição da aprendizagem organizacional. 2001. Tese (Doutorado em Administração) - Universidade Federal do Rio Grande do Sul.

CANNON, M. D.; EDMONDSON, A. C. Confronting failure: antecedents and consequences of shared beliefs about failures in organizational work groups. Journal of Organizational Behavior, v. 22, n. 2, p. 161-177, 2001.

CANNON, M. D.; EDMONDSON, A. C. Failing to learn and learning to fail (intelligently): how great organizations put failure to work to innovate and improve. Long Range Planning, v. 38, n. 3, p. 299-319, 2005.

CHIVA R; ALEGRE. J.; LAPIEDRA, R. Measuring organizational learning capability among the workforce. International Journal of Manpower, v. 28, n. 3, p. 224-242, 2007

DE SOUZA MARTINS, H. H. T. Metodologia qualitativa de pesquisa. Educação e pesquisa, v. 30, n. 2, p. 289-300, 2004.

DIAS, T. R. F. V.; MARTENS, C. D. P.. Competências e aprendizagem empreendedora no contexto de insucesso empresarial: proposição de um modelo conceitual. Desenvolvimento em Questão, v. 14, n. 33, p. 172-202, 2016.

DORNELAS, J. C. A. Empreendedorismo: transformando idéias em negócios. Rio de Janeiro, RJ: Elsevier, 2001.

EDMONDSON, A. C. Psychological safety and learning behavior in work teams. Administrative Science Quarterly, v. 44, n. 2, p.350-383, 1999.

FILION, L. J. Empreendedorismo: empreendedores e proprietários-gerentes de pequenos negócios. Revista de administração, v. 34, n. 2, p. 5-28, 1999.

GODOI, C. K. Perspectivas de análise do discurso nos estudos organizacionais. In: GODOI, C. K; MELLO, R.B.; SILVA. A.B. (org.). Pesquisa qualitativa em estudos organizacionais: paradigmas, estratégias e métodos. São Paulo: Saraiva, 2006.

GODOI, C. K.; MATTOS, P.L.C.L. Entrevista qualitativa: instrumento de pesquisa e evento dialógico. In: GODOI, C. K; MELLO, R.B.; SILVA. A.B. (org.). Pesquisa qualitativa em estudos organizacionais: paradigmas, estratégias e métodos. São Paulo: Saraiva, 2006. 
HARTEIS, C.; BAUER, J.; GRUBER, H. The culture of learning from mistakes: how employees handle mistakes in everyday work. International Journal of Educational Research, n. 47, p. 223-231, 2008.

HISRICH, R.D.; PETERS, M.P. Empreendedorismo. 5. Ed. Porto Alegre: Bookman, 2004. KOLB, D. A.; RUBÍN, I. M.; MCINTYRE, J. M. Psicologia organizacional: uma abordagem vivencial. Atlas, 1978.

KOLB, D. Experiential learning: experience as the source of learning and development. New Jersey: Prentice Hall, 1984.

KOLODNER, J. L. Towards an understanding of the role of experience in the evolution from novice to expert. International Journal of Man-Machine Studies, v. 19, n. 5, p. 497-518, 1983.

LOPEZ, S. P.; PÉON, J. M. M.; ORDÁS, C. J. V. Organizational learning as a determining factor in business performance. The learning organization, v. 12, n. 3, p. 227-244, 2005.

MAN, T. W. Y. Exploring the behavioural patterns of entrepreneurial learning: A competency approach. Education e Training, v. 48, n. 5, p. 309-321, 2006.

MARSICK, V. J.; WATKINS, K. E. Demonstrating the value of an organization's learning culture: the dimensions of the learning organization questionnaire. Advances in Developing Human Resources, v. 5, n. 2, p. 132-151, 2003.

MARSICK, V.; WATKINS, K. Lessons from informal and incidental learning. In: BURGOYNE, J; REYNOLDS, M.(org) Management learning: integrating perpectives in theory and practice. London: Sage Publications, 1997.

MATIAS, J. P.; GOMES, A. F.; LIMA ALVES, R. de C. O.; SANTANA, W. G. P. Processo empreendedor: um estudo com músicos independentes em Vitória da Conquista - BA. Anais... X EGEPE - Encontro de Estudos sobre Empreendedorismo e Gestão de Pequenas Empresas, 2018.

MERRIAM, S. B. A. Qualitative research in practice: Examples for discussion and analysis. San Francisco, CA: Jossey-Bass, 2002.

MORRISON, A.; BERGIN-SEERS, S. Pro-Growth small businesses: learning "Architecture". Journal of Management Development, v. 21, n. 5, p. 388-400, 2002.

MURPHY, J. Self-Evaluation \& Effectiveness Review for Entrepreneurial Learning and Decision Making. Journal of Enterprising Culture, v. 1, n. 1, p. 109-131, 1993.

OHLSSON, S. Learning from performance errors. Psychological Review, v. 103, n. 2, p. 241-262, 1996.

PINTO, C. O. F.; RUPPENTHAL, J. E.; SANTINI, S.; SILUK, M. H. P. O Empreendedorismo e sua contribuição para o crescimento econômico no Brasil. Anais... XVIII Simpósio de Engenharia de Produção, 2010.

POLITIS, D. The Process of Entrepreneurial Learning: A conceptual Framework. Entrepreneurship Theory and Practice, v. 29, n. 4, p. 399-424, 2005.

PRIYANTO, S. H.; SANDJOJO, I. Relationship between entrepreneurial learning, entrepreneurial competencies and venture success: Empirical study on SMEs. International Journal Entrepreneurship and Innovation Management, v. 5, n. 5/6, p. 454-467, 2005.

PUTZ, D.; SCHILLING, J.; KLUGE, A.; STANGENBERG, C. Measuring organizational learning from errors: development and validation of an integrated model and questionnaire. Management Learning, v. 44, n. 5, p. 511-536, 2012. 
RAE, D. Understanding entrepreneurial learning: a question of how? International Journal of Entrepreneurial Behaviour \& Research, v. 6, n. 3, p. 145-159, 2000.

RAE, D.; CARSWELL, M. Using a life-story approach in researching entrepreneurial learning: The development of a conceptual model and its implications in the design of learning experiences. Education \& Training, v. 42, n. 4/5, p. 220-227, 2000.

RAMANUJAM, R.; GOODMAN, P. Latent errors and adverse organizational consequences: A conceptualization. Journal of Organizational Behavior: The International Journal of Industrial, Occupational and Organizational Psychology and Behavior, v. 24, n. 7, p. 815-836, 2003.

ROESCH, S. M. A. Projetos de estágio e de pesquisa em administração: guia para estágios, trabalhos de conclusão, dissertações e estudo de caso. 3 Ed. São Paulo: Atlas, 2006.

SCHUMPETER, J. A. Teoria do desenvolvimento econômico. (L. Schlaepfer, Trad.) Rio de Janeiro: Fundo de Cultura. 1961.

TIMMONS, J.; SPINELLI, S. New venture creation: entrepreneurship for the 21 st century. 6 Ed. Boston: Irwin McGraw Hill,2004.

TJOSVOLD, D.; ZI-YOU, Y. U.; HUI, C. Team learning from mistakes: the contribution of cooperative goals and problem-solving. Journal of management studies, v. 41, n. 7, p. 1223$1245,2004$.

TUCKER JR., L. R. Entrepreneurial Learning Experience: The Academic Responsibility. Journal of Business Education, v. 56, n. 4, p. 132-135, 1981.

VAN DYCK, C.; FRESE, M.; BAER, M.; SONNENTAG, S. Organizational error management culture and its impact on performance: a two-study replication. Journal of Applied Psychology, v. 90, n. 6, p. 1228-1240, 2005.

VAN WOERKOM, M.; CROON, M. Operationalising critically reflective work behaviour. Personnel Review, v. 37, n. 3, p. 317-331, 2008.

VOGT, S.; BULGACOV, Y. L. M. Aprender, Empreender e Aprender: a Perspectiva da Prática para o Entendimento do Processo da Aprendizagem Empreendedora. Revista da Micro e Pequena Empresa, v. 12, n. 3, p. 28, 2018.

WANG, C. L.; CHUGH, H. Entrepreneurial Learning: Past Research and Future Challenges. International Journal of Management Reviews, v. 16, n. 1, p. 24-61, 2014.

ZAMPIER, M.; TAKAHASHI, A. D. W. Competências empreendedoras e processo de aprendizagem empreendedora: modelo conceitual de pesquisa. Cadernos EBAPE. BR, v. 9, Edição Especial, p. 564-585, 2011.

ZHAO, B; OLIVERA, F. Error reporting in organizations. The Academy of Management Review, v. 31, n. 4, p. 1012-1030, 2006. 